\title{
Years of life lost through Down's syndrome
}

\author{
MARSHALL B. JONES \\ From the Department of Behavioral Science, Pennsylvania State University College of Medicine, \\ Hershey, Pennsylvania 17033, USA
}

SUMMARY A congenital genetic condition does not act either as a cause of death or at the time of death only. Hence, years of life lost through such a condition cannot be calculated in the same way as for a conventional cause of death. The main difference is that a cause of death acting at age $\mathrm{x}$ cuts off as many years of life as the dead person might otherwise have expected to live (life expectancy at age $\mathrm{x}$ ), whereas a congenital genetic condition exposes an affected person to a different schedule of life-threatening risks from birth onwards. In the latter case, years of life lost is calculated as the difference in life expectancy at birth for affected and non-affected persons. This reasoning is worked out in algebraic form and then applied to Down's syndrome. The data base is provided by two large and recent studies, one in Massachusetts and the other in Denmark, of mortality rates among all cases of Down's syndrome, whether in an institution or not, born during a given period of years or living at a given point in time in a fixed geographical area. So calculated, years of life lost through Down's syndrome relative to the United States general population in 1970 was $53 \cdot 6$ years per 1000 livebirths. Prenatal mortality is also discussed.

Patients with Down's syndrome die at an earlier age than other people of the same sex and race (Carter, 1958; Collmann and Stoller, 1963; Benda, 1969; Fabia and Drolette, 1970; Deaton, 1973; Øster et al., 1975). In addition, we have reason to believe that if these patients had exactly the same genomes as they have, except for trisomy at chromosome 21 , they would live as long as other people. In general terms, therefore, it makes sense to say that Down's syndrome is a life-shortening condition or that because of it so many years of life are lost. Any attempt to be more specific, however, runs into difficulty because Down's syndrome is not a cause of death in the usual sense, and does not satisfy the assumptions implicit in the accepted actuarial procedures for calculating years of life lost (Jordan, 1952). The purpose of this paper is, first, to consider how, in general, years of life lost should be calculated for a congenital genetic condition, and then to carry out such a calculation for Down's syndrome. A concluding section discusses prenatal mortality because of trisomy 21 .

\section{Years of life lost}

Years of life lost is ordinarily calculated for a cause Received for publication 6 December 1978 of death as given in the international classification of causes of death (World Health Organization, 1977). In theory, the analysis begins with a multipledecrement life table that includes cause of death $\mathrm{k}$ as one component. Years of life lost is defined as the gain in life expectancy at birth (or, which is the same thing in a life table population, average age at death) that would result if the partial forces of decrement associated with cause $\mathrm{k}$ were eliminated. The partial forces of decrement $\mu_{\mathrm{x}}{ }^{(\mathrm{k})}$ are then deleted for all ages (x) and a new life table constructed from the remaining forces of decrement. In the new life table, no-one dies of cause $\mathrm{k}$ and, in addition, slightly more now die from other causes; that is, the procedure corrects for competing risks (Cornfield, 1957; Gail, 1975). Years of life lost then equals the difference in life expectancy at birth in the new and old life table populations.

In practice, this process can frequently be abbreviated, especially if a cause of death is uncommon and still more if it acts over a narrow span of years. Under these circumstances, deleting the partial forces of decrement $\mu_{\mathrm{x}}{ }^{(\mathrm{k})}$ will have little effect on life expectancy at age $x$. Hence, to calculate years of life lost through cause $\mathrm{k}$ all we need to do is to multiply life expectancy at age $\mathrm{x}$ by the number of persons per 100000 born who die at age $\mathrm{x}$ from cause $\mathrm{k}$ and 
then find the total. The result is the number of years of life lost per 100000 liveborn through cause $k$.

This calculation is carried out on the assumption that a cause of death acts at the time of death only. Accidental death is probably the clearest example. If a person who, in the old life table population, would have died by accident at age 44 does not do so, then his life prospects are the same as those of other 44-year-olds. Hence, the number of years cut off by his death is his life expectancy at 44 . It occasionally happens that an investigator calculates years of life lost by taking the difference between age at death and life expectancy at birth (Dempsey, 1947; Fielding and Walsh, 1976). This procedure is incorrect (Greville, 1948) because a person aged 44 has already survived many risks of death and can expect to live to an appreciably riper age than he could have as a newborn.

A congenital genetic condition differs from a traditional cause of death in two basic ways. Firstly, it can be taken to act continuously from the moment of birth. Secondly, it does not act as a cause of death but, rather, as a risk-altering state. The age specific risks of death from pneumonia, for example, are much greater for patients with Down's syndrome than they are for other people, especially in adolescence (Øster et al., 1975, Table 4). The age specific risks of death from heart disease are also greatly raised among people with Down's syndrome, again in adolescence especially, but even more so in childhood (Øster et al., 1975, Table 5). Were trisomy 21 to be prevented altogether, the effect would not be to eliminate any cause of death, but to distribute the deaths of those persons who would otherwise have had Down's syndrome in the same proportions, relative to why and at what age a person dies, as the deaths of other people. In effect, people with Down's syndrome are born into a different life table than other people. Except by accident, the risks to life are not the same for them as they are for other people at any age.

By general consent, years of life lost is defined as the number of years of life that would eventually be gained if the cause or condition under study were somehow eliminated. Consider, then, the average age at death for a person with Down's syndrome, $\bar{y}_{\text {Ds }}$, and the expectation of life at birth for everyone else, e̊. $e_{o}^{\prime}$ If Down's syndrome is eliminated, then everyone who would have lived $\bar{y}_{D s}$ years now lives $\varepsilon_{\mathrm{o}}^{\prime}$ years. Hence, for each such person the gain in years of life lived equals $\left(\AA_{o}^{\prime}-\bar{y}_{D S}\right)$.

Let us see, then, exactly what we need to know in order to calculate years of life lost through Down's syndrome. If $I_{D s}$ is the incidence of Down's syndrome per 100000 born, then years of life lost through Down's syndrome is

$$
\begin{gathered}
Y_{D S}=I_{D S}\left(e_{o}^{\prime}-y_{D S}\right) \text { years per } 100000 \\
\text { liveborn. }
\end{gathered}
$$

$I_{\mathrm{Ds}}$ and $\mathrm{y}_{\mathrm{D}}$ can be determined from reports Down's syndrome and $\dot{e}_{o}^{\prime}$ can be inferred from thi same information and published life expectanc figures. It is not, of course, quite the same as pub lished life expectancy at birth, $\stackrel{\mathrm{e}}{o}_{\mathrm{o}}$, because the published figure includes the deaths of persons with Down's syndrome, whereas $\dot{e}_{\circ}^{\prime}$ does not. The tw $\vec{\emptyset}$ figures are, however, simply related:

$$
\check{\mathrm{e}}_{\mathrm{o}}^{\prime}=\frac{100000 \mathrm{e}_{\mathrm{o}}-\mathrm{I}_{\mathrm{DS}} \mathrm{y}_{\mathrm{DS}}}{100000-\mathrm{I}_{\mathrm{DS}}} .
$$

Substituting in formula (1) then gives us

$$
Y_{L L}=I_{D S}\left(\stackrel{e}{\odot}_{0}-\bar{y}_{D S}\right)+\frac{I_{D S}^{2}\left(\dot{e}_{o}-\bar{y}_{D S}\right)}{100000-I_{D S}} .
$$

For most genetic diseases the second term is very small and can safely be ignored. We will calculate iQ however, if only to make clear that it is negligible?

Formulas (1) and (2), and the reasoning th underlies them, apply to genetic conditions which manifest themselves at birth only. Diseases wit delayed onset require special treatment.

\section{Down's syndrome}

The incidence of Down's syndrome in the UK birth has been reliably estimated as 1 in 660 (Carte and MacCarthy, 1951). Amniocentesis might easi change this figure but as of 1970, the date we will use for our calculations, this figure was still generalk accepted for the US also (Nora and Fraser, 1974).

Superficially, the sex distribution at birth appears slightly to favour the males. Record and Smith (1953) reported that in a series of 252 persons born witi Down's syndrome in Birmingham, England, 55.4\% were male and $44.6 \%$ were female. Most of the evidence, however, supports the view that in ear? infancy especially, but to some extent throughout the first year of life, female infants with Down's sy drome die at a greater rate than their male counter parts (Carter, 1958; Collmann and Stoller, 196\%; Forssman and Akesson, 1965; Fabia and Drolett倌 1970). Therefore, any failure of ascertainment in the first few days or weeks after birth will lead overestimation of the sex ratio at birth. Record arfe Smith (1955) believed that an error of this sort was involved in their own data. In their opinion, the ratio at birth which they obtained was 'probably to high'. We will proceed, therefore, on the assumption that with complete ascertainment at birth, male and female neonates with Down's syndrome would of equal numbers.

Life expectancy among patients with Downs 
syndrome has increased in the last three or four decades. In 1954, the average age at death of persons with Down's syndrome in institutions in Australia was slightly over 10 years (Brothers and Jago, 1954). In 1961, also in Australia, the average age at death was 16.2 years (Collmann and Stoller, 1963). Benda (1969) estimated that in the United States life expectancy of a person with Down's syndrome in an institution who survived infancy was 'about 9 years' in 1929 and ' 12 to 15 years' in 1945 . On the basis of deaths at the Walter E. Fernald State School over the years 1947 to 1965 , Benda estimated that the life expectancy of a patient in an institution was 'about $30 \cdot 2$ years'.

This history makes it clear that, if it is to have current relevance, any calculation of years of life lost through Down's syndrome must be based on recent data. The repeated references in the preceding paragraph to persons in institutions underline a second point. Because of selection or, perhaps, a greater risk of infection, the death rate appears to be higher among patients in institutions than among people with Down's syndrome living with their families (Deaton, 1973; Øster et al., 1975). It is desirable, therefore, to base the study on recent reports that include all persons with Down's syndrome in a given area, whether in institutions or not; if only persons in institutions are included, years of life lost through Down's syndrome will be overestimated.

Fortunately, we have two large studies of mortality in Down's syndrome that satisfy both of these requirements. Fabia and Drolette (1970) present sex specific life tables up to 10 years of age, based on all cases of Down's syndrome born alive from 1950 to 1966 to residents of Massachusetts, a total of 2421 cases. Øster et al. (1975) present sex specific life tables from 5 to 80 years of age, based on all persons with Down's syndrome living in a certain area of Denmark in 1949, a total of 526 cases. Fortunately, too, general conditions affecting life expectancy are much the same in Denmark and the United States (Preston et al., 1972).

The Danish authors had data for the first 5 years of life but considered it 'not sufficient for calculations'. It is precisely for these years, however, that the Massachusetts data are most complete. For the years from 5 to 10, the two studies are in essential agreement for the males. In the Danish study $94.5 \%$, and in the American study $93.4 \%$, of all males who survived until 5 years of age were still alive on their 10th birthday. For the females, however, the Danish study showed a lower survival rate over these 5 years than the American study, $88.3 \%$ versus $95.0 \%$. Because of their greater size, we will use the American data for 5 to 9 years of age.
Table No surviving $\left(l_{x}\right)$ and No dying $\left(d_{x}\right)$ per 100 births with Down's syndrome by sex for single years of age up to 4- and 5-year intervals thereafter. From Fabia and Drolette (1970) and Øster et al. (1975).

\begin{tabular}{|c|c|c|c|c|}
\hline \multirow{2}{*}{$\begin{array}{l}\text { Age } \\
\text { interval }\end{array}$} & \multicolumn{2}{|l|}{ Males } & \multicolumn{2}{|c|}{ Females } \\
\hline & $l_{x}$ & $d_{x}$ & $l_{x}$ & $d_{x}$ \\
\hline Infancy & $100 \cdot 0$ & $21 \cdot 3$ & $100 \cdot 0$ & $25 \cdot 9$ \\
\hline 1 & $78 \cdot 7$ & $3 \cdot 3$ & $74 \cdot 1$ & $4 \cdot 3$ \\
\hline 2 & $75 \cdot 4$ & $1 \cdot 8$ & $69 \cdot 8$ & $2 \cdot 5$ \\
\hline 3 & $73 \cdot 6$ & $1 \cdot 2$ & $67 \cdot 3$ & 1.4 \\
\hline 4 & $72 \cdot 4$ & 0.5 & $65 \cdot 9$ & 0.8 \\
\hline $5-9$ & $71 \cdot 9$ & $4 \cdot 7$ & $65 \cdot 1$ & $3 \cdot 2$ \\
\hline $10-14$ & $67 \cdot 2$ & $2 \cdot 2$ & $61 \cdot 9$ & 0.0 \\
\hline $15-19$ & $65 \cdot 0$ & $2 \cdot 5$ & $61 \cdot 9$ & $1 \cdot 0$ \\
\hline $20-24$ & $62 \cdot 5$ & $3 \cdot 1$ & $60 \cdot 9$ & 1.6 \\
\hline $25-29$ & $59 \cdot 4$ & $1 \cdot 9$ & $59 \cdot 3$ & $2 \cdot 2$ \\
\hline $30-34$ & $57 \cdot 5$ & $2 \cdot 2$ & $57 \cdot 1$ & $1 \cdot 1$ \\
\hline $35-39$ & $55 \cdot 3$ & $2 \cdot 8$ & 56.0 & 0.6 \\
\hline $40-44$ & $52 \cdot 5$ & $4 \cdot 9$ & 55.4 & $1 \cdot 5$ \\
\hline $45-50$ & $47 \cdot 6$ & $4 \cdot 9$ & 53.9 & 7.9 \\
\hline $50-54$ & $42 \cdot 7$ & $2 \cdot 7$ & $46 \cdot 0$ & $6 \cdot 4$ \\
\hline $55-60$ & 40.0 & $10 \cdot 1$ & $39 \cdot 6$ & 9.0 \\
\hline $60-64$ & 29.9 & $14 \cdot 1$ & $30 \cdot 6$ & $14 \cdot 9$ \\
\hline $65-69$ & $15 \cdot 8$ & $11 \cdot 3$ & $15 \cdot 7$ & 9.4 \\
\hline $70-74$ & $4 \cdot 5$ & 3.4 & $6 \cdot 3$ & $3 \cdot 8$ \\
\hline $75-79$ & $1 \cdot 1$ & $1 \cdot 1$ & $2 \cdot 5$ & $2 \cdot 5$ \\
\hline Total & - & $100 \cdot 0$ & - & $100 \cdot 0$ \\
\hline
\end{tabular}

The Table presents the number surviving $\left(l_{x}\right)$ and the number dying $\left(d_{x}\right)$ per 100 births with Down's syndrome for single years up to 4- and 5-year intervals thereafter. For 0 to 9 years of age the figures are calculated from Fabia and Drolette (1970), thereafter from Øster et al. (1975). The average age at death for those patients who died in infancy was 4 months for both sexes (Fabia and Drolette, 1970). Assuming that otherwise all deaths are distributed uniformly over their respective age intervals, the average age at death for males is 35.7 and for females $35 \cdot 5$. In 1970 , life expectancy at birth in the general United States population was $67 \cdot 1$ years for males and $\mathbf{7 4 . 8}$ years for females (National Center for Health Statistics, 1974). Therefore, applying equation (2), years of life lost through Down's syndrome is $2378 \cdot 8+3 \cdot 6=2382 \cdot 4$ years per 50000 born for the males and $2977 \cdot 3+4 \cdot 5=$ $2981 \cdot 8$ years per 50000 born for the females. For the two sexes together, YLL $\mathrm{YL}_{\mathrm{Ds}}$ is $5364 \cdot 2$ years per 100000 persons born alive, or a little more than $53 \frac{1}{2}$ years for every 1000 livebirths. Since the second terms (3.6 and $4 \cdot 5)$ are tiny and Down's syndrome is more common than the great majority of congenital genetic disorders, it is clear that $\dot{e}_{o}$ may be substituted for $\hat{e}_{o}^{\prime}$ in formula (1) with no appreciable error.

\section{Prenatal mortality}

Years of life lost does not reflect the total damage 
done by trisomy 21 . It does not, for example, include the reduction in the quality of life resulting from Down's syndrome. Neither does it include the anguish experienced by the parents of a child with Down's syndrome or the additional cost to them or to society of rearing and maintaining such a child.

Prenatal losses are another form of damage which is not included. Years of life lost is conventionally calculated from birth and for livebirths only. As a result, it systematically underestimates the amount of mortality through any condition which, like trisomy 21, carries an increased risk of fetal death. This additional mortality will be treated here as a separate issue.

A recent review (Carr and Gedeon, 1977) estimates the frequency of spontaneous abortions at $15 \%$. The same review estimates that roughly half of all spontaneous abortions involve chromosomal anomalies, that half of the anomalies are trisomies, and that roughly one tenth of the trisomies involve chromosome 21 . These results are still tentative and subject to considerable uncertainty, but whether or not they permit us to calculate 'years of life lost' through fetal death is not primarily a technical question. To say that spontaneous abortion abbreviates a human life is to assume that such a life is already in existence. This assumption, however, is decidedly controversial. Many people would say that no years of life are lost through fetal death in the first or second trimester because, in their opinion, up to that point in fetal development human life has not yet begun. Since this question is currently under widespread discussion, it will not be pursued here but, instead, it will simply be noted that trisomy 21 also occasions a certain amount of prenatal damage.

The main purpose in calculating years of life lost is to indicate the general impact of a disease or condition (Hemminki et al., 1976). It is on this basis that vascular disease is often said to be the most serious health problem in the USA today (for example, Wetzler, 1976). In certain circumstances, however, years of life lost or closely related statistics may also be used to assess the costs or benefits of particular forms of medical intervention. We have just determined that a liveborn child with Down's syndrome can expect to live $35 \cdot 6$ years. It follows that induced abortion after amniocentesis, occurring as it now does toward the end of the second trimester of pregnancy (Omenn, 1978), can be expected to cut off 3 months of prenatal and $35 \cdot 6$ years of postnatal 1 ife. Clearly, a decision as to abortion involves other considerations, for example, that the life cut off is a life with Down's syndrome or, on the other side of he issue, that the parents may not be able to have nother child or can have one only at additional sychological, financial, or moral costs. Neverthe- less, expected length of postnatal life is also aff important consideration.

\section{References}

Benda, C. E. (1969). Down's Syndrome: Mongolism and $i$ Management, pp. 45-47. Grune and Stratton, New York

Brothers, C. R. D., and Jago, G. C. (1954). Report on the longevity and the cause of death in mongoloidism in the State of Victoria. Journal of Mental Science, 100, 5800 586.

Carr, D. H., and Gedeon, M. (1977). Population cytogeneti $\overrightarrow{E g}$ of human abortuses. In Population Cytogenetics: Studies Humans. Ed. by E. B. Hook and I. H. Porter. Academi Press, New York.

Carter, C. O. (1958). A life-table for mongols with the causes of death. Journal of Mental Deficiency Researckr 2, 64-74.

Carter, C. O., and MacCarthy, D. (1951). Incidence mongolism and its diagnosis in the newborn. British Journd of Social Medicine, 5, 83-90.

Collmann, R. D., and Stoller, A. (1963). Data on mongolis $\overrightarrow{\vec{B}}$ in Victoria, Australia: prevalence and life expectation Journal of Mental Deficiency Research, 7, 60-68.

Cornfield, J. (1957). The estimation of the probability developing a disease in the presence of competing risks. American Journal of Public Health, 47, 601-607.

Deaton, J. G. (1973). The mortality rate and cause of deated among institutionalized mongols in Texas. Journal of Mental Deficiency Research, 17, 117-122.

Dempsey, M. (1947). Decline in tuberculosis: the death rat fails to tell the entire story. American Review of Tuberculosi 56, 157-164.

Fabia, J., and Drolette, M. (1970). Life tables up to age 10 for mongols with and without congenital heart defect. Journal of Mental Deficiency Research, 14, 235-242.

Fielding, J. E., and Walsh, D. C. (1976). Comprehensivo health care and motor-vehicle safety. New England Journat of Medicine, 294, 841-843.

Forssman, H., and Akesson, H. O., (1965). Mortality in patients with Down's syndrome. Journal of Ment Deficiency Research, 9, 146-149.

Gail, M. (1975). A review and critique of some models used in competing risk analysis. Biometrics, 31, 209-222.

Greville, T. N. E. (1948). Comments on Mary Dempseys article on Decline in tuberculosis: the death rate fails tell the entire story'. American Review of Tuberculosis, $5 \bar{z}$ 417-419.

Hemminki, E., Hemminki, K., Hakulinen, T., and Hakamar M. (1976). Increase in years of life after eliminating causes of death: significance for health priorities. Scandinaviaß Journal of Social Medicine, 4, 1-6.

Jordan, C. W. (1952). Life Contingencies. Society for Actuaries. Chicago.

National Center for Health Statistics (1974). Vital Statisti@s of the United States, 1970: Vol. II, Section 5, Life Tables US Department of Health, Education, and Welfare Washington DC.

Nora, J. J., and Fraser, R. C. (1974). Medical Genetic® Principles and Practice, p. 29. Lea and Febiger, Philadelphia.

Omenn, G. S. (1978). Prenatal diagnosis of genetic disorders Science, 200, 952-958.

Øster, J., Mikkelsen, M., and Nielsen, A. (1975). Mortali® and life-table in Down's syndrome. Acta Paediatrieg Scandinavica, 64, 322-326. 
Preston, S. H., Keyfitz, N., and Schoen, R. (1972). Causes of Death: Life Tables for National Populations. Seminar Press, New York.

Record, R. G., and Smith, A. (1955). Incidence, mortality and sex distribution of mongoloid defectives. British Journal of Preventive and Social Medicine, 9, 10-15.

Wetzler, H. P. (1976). Loss of working years in accidents. New England Journal of Medicine, 294, 1348.
World Health Organization (1977). Manual of the International Classification of Diseases, Injuries, and Causes of Death. WHO, Geneva.

Requests for reprints to Professor M. B. Jones, Department of Behavioral Science, Milton S. Hershey Medical Center, Pennsylvania State University, Hershey, Pennsylvania 17033, USA. 